\title{
Experimental Research on Parameter Optimization for High Efficiency Hard Turning of Ultrahigh Strength Steel 42CrMo
}

\author{
Pei YAN, Junyi ZHU, Zeyu PENG, Peng WANG, Li JIAO, Xibin WANG \\ Key Laboratory of Fundamental Science for Advanced Machining, Beijing Institute of Technology, Beijing 100081, PR \\ China, E-mail: pyan@bit.edu.cn
}

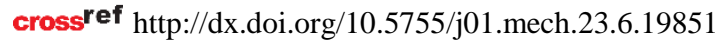

\section{Introduction}

Ultrahigh strength steel is a new kind of structural materials [1] developed from constructional alloy steels, which with the tensile strength over $1500 \mathrm{MPa}$ or yield strength over $1380 \mathrm{MPa}$. They are used chiefly in the aircraft landing gear and main girders, crankshaft and connecting rod of engine, and other structural components in highly stressed [2]. Benefited from composite reinforcement effect of various mechanisms like martensitic strengthening, grain refinement strengthening, compound dispersion strengthening and solid solution strengthening, ultrahigh strength steels are with excellent properties such as high strength, specific strength, yield ratio, adequate toughness and fracture toughness.

While, ultrahigh strength steel is a typical difficultto-cut material [3]: as the shear strength is very high, the cutting force will rise with tool violent vibration; due to low thermal conductivity, the cutting temperature is very high, resulting in the machining error by thermal deformation of the workpiece. Because of high strength, toughness, and low thermal conductivity, there are huge pressure, extremely high temperature and heat concentration at cutting area, which will aggravate the wear of rake face and flank face [4], and the tool life is often very short [5]. In realistic machining process of ultrahigh strength steel, the machining efficiency is very low, with serious tool wear. High efficiency and high quality processing of ultrahigh strength steel is truly a significant conversation.

In actual turning process, there are many factors that affect the cutting efficiency and surface quality [6-8], such as cutting tool material, cutting tool geometry, cutting parameter, cutting fluid, etc. While, the most influential factor that can be controlled are cutting parameters, which is also the simplest and economic. Reasonable selection of cutting parameters can effectively improve the production efficiency and quality, and reduce the cost.
$42 \mathrm{CrMo}$ is a typical ultrahigh strength steel which is widely used as crankshaft and connecting rod of engine. In this paper, the influence of cutting parameters on cutting force and surface quality during dry turning process of ultrahigh strength steel $42 \mathrm{CrMo}$ was investigated. This study gave experimental support for process parameters optimization, comprehensive considering processing efficiency, tool wear and machined surface quality.

\section{Experimental procedures}

Cutting tests were carried out on a HAWK TC-150 lathe (Cincinnati, USA) without cutting fluid during the cutting processes. According to basic cutting experiment earlier and literature, the cutting tools selected were coated cemented carbide inserts DNMG150408GS (KYOCERA Corporation, Japan) with rake angle $\gamma_{\mathrm{o}}=10^{\circ}$, flank angle $\alpha_{\mathrm{o}}=0^{\circ}$, tool angle $\varepsilon_{r}=55^{\circ}$. The workpiece material was ultrahigh strength steel $42 \mathrm{CrMo}$ which was used as transmission shaft in actual production, with length $160 \mathrm{~mm}$ and diameter 100 mm. Main composition and mechanical properties of 42CrMo were shown in Table 1 and Table 2.

In this study, the cutting force and surface roughness were considered as the test indexes, and cutting speed, feed rate and cutting depth were the primary factors. Orthogonal design and analysis were used, and the table of L16 $\left(4^{3}\right)$ was adopted. The range of cutting parameters was selected based on preliminary tests as well as the literature data, in which the tool life and machined surface roughness were both acceptable, shown in Table 3.Three-dimensional cutting forces were obtained by $9257 \mathrm{~B}$ piezoelectric quartz dynamometer (Kistler, Swiss), and cutting force was calculated $\left(F=\sqrt{F x^{2}+F y^{2}+F z^{2}}\right)$. Surface roughness $R a$ was measured four times in different axis position and averaged, with a roughness tester SRT-6200 (Landtek, China). Wear of the tool was measured using a confocal laser scanning microscope VK-100 (KEYENCE, Japan).

Table 1

Element composition of 42CrMo (wt.\%)

\begin{tabular}{|c|c|c|c|c|c|c|c|c|}
\hline Element & $\mathrm{Cr}$ & $\mathrm{C}$ & $\mathrm{Si}$ & $\mathrm{Mn}$ & $\mathrm{Mo}$ & $\mathrm{S}$ & $\mathrm{P}$ & $\mathrm{Ni}$ \\
\hline Wt.\% & $0.90 \sim 1.20$ & $0.38 \sim 0.45$ & $0.17 \sim 0.37$ & $0.50 \sim 0.80$ & $0.15 \sim 0.25$ & $\leq 0.035$ & $\leq 0.035$ & $\leq 0.030$ \\
\hline
\end{tabular}

Table 2

Mechanical properties of $42 \mathrm{CrMo}$

\begin{tabular}{|c|c|c|c|c|}
\hline $\begin{array}{c}\text { Density } \rho \\
\mathrm{g} / \mathrm{cm}^{3}\end{array}$ & $\begin{array}{c}\text { Thermal conductivity } \lambda \\
\mathrm{W} / \mathrm{m} \cdot \mathrm{K}\end{array}$ & $\begin{array}{c}\text { Tensile strength } \sigma_{b} \\
\mathrm{MPa}\end{array}$ & $\begin{array}{c}\text { Yield limit } \sigma_{s} \\
\mathrm{MPa}\end{array}$ & $\begin{array}{c}\text { Hardness } \\
\text { HRC }\end{array}$ \\
\hline 7.85 & 45 & 1080 & 930 & 36 \\
\hline
\end{tabular}




\section{Results and discussion}

According to selected ranges of cutting parameters and the table of L16 $\left(4^{3}\right)$, each experiment was carried out, and the cutting forces and surface roughness were measured and calculated. The results were denoted in Table 4.

\subsection{Cutting force and surface roughness $R a$}

The range table of cutting force $F$ and surface roughness $R a$ were shown in Table 5 and 6, and the trend chart was shown in Fig. 1. Three-dimensional cutting forces and the resultant force were basically decreased as the increase of cutting speed, and increased as the increase of feed rate and cutting depth. When cutting speed was over 160 $\mathrm{m} / \mathrm{min}$, the cutting force showed a slightly increase trend, that was mainly because that the cutting temperature was too high with high speed, which resulted in serious tool wear. The rapid wear of the tool then caused the cutting force increased. The exponential form considering cutting speed, feed rate and cutting depth was adopted for the modeling of cutting force and surface roughness. By the aid of data analysis software Minitab, the experiment results were fitted and the regression coefficients were calculated, then the multiple linear regression model was obtained. Within the selected range of experimental parameters, the empirical formula of the cutting force was:

$$
F=1887.484 v^{-0.017} f^{0.529} a_{p}^{1.052} .
$$

Table 3

Ranges of cutting parameters

\begin{tabular}{|c|c|c|c|c|}
\hline \multirow{2}{*}{ Parameter } & \multicolumn{4}{|c|}{ Levels for each parameter } \\
\cline { 2 - 5 } & 1 & 2 & 3 & 4 \\
\hline $\begin{array}{c}\text { Cutting speed, } v \\
(\mathrm{~m} / \mathrm{min})\end{array}$ & 80 & 120 & 160 & 200 \\
\hline $\begin{array}{c}\text { Feed rate, } f \\
\text { (mm/rev) }\end{array}$ & 0.10 & 0.15 & 0.20 & 0.25 \\
\hline $\begin{array}{c}\text { Depth of cut, } a_{\mathrm{p}} \\
(\mathrm{mm})\end{array}$ & 0.40 & 0.60 & 0.80 & 1.00 \\
\hline
\end{tabular}

Table 4

Experimental setup and the result of $F$ and $R a$

\begin{tabular}{|c|c|c|c|c|c|c|c|c|}
\hline No. & $v$ & $f$ & $a_{p}$ & $F_{X}$ & $F_{y}$ & $F_{z}$ & $F$ & $R a$ \\
\hline 1 & 80 & 0.10 & 0.4 & 151.9 & 79.4 & 141.5 & 222.258 & 2.164 \\
\hline 2 & 80 & 0.15 & 0.6 & 265.8 & 217.1 & 325.3 & 472.866 & 0.986 \\
\hline 3 & 80 & 0.20 & 0.8 & 387.5 & 372.0 & 561.3 & 776.916 & 3.743 \\
\hline 4 & 80 & 0.25 & 1.0 & 424.8 & 437.1 & 764.2 & 977.503 & 3.547 \\
\hline 5 & 120 & 0.10 & 0.6 & 231.5 & 202.8 & 244.1 & 392.817 & 0.563 \\
\hline 6 & 120 & 0.15 & 0.4 & 157.8 & 98.9 & 164.0 & 248.141 & 0.711 \\
\hline 7 & 120 & 0.20 & 1.0 & 368.4 & 412.1 & 622.7 & 832.647 & 2.211 \\
\hline 8 & 120 & 0.25 & 0.8 & 350.2 & 271.8 & 499.9 & 668.143 & 1.463 \\
\hline 9 & 160 & 0.10 & 0.8 & 239.6 & 218.3 & 261.3 & 416.342 & 1.991 \\
\hline 10 & 160 & 0.15 & 1.0 & 341.0 & 400.1 & 508.6 & 731.461 & 0.975 \\
\hline 11 & 160 & 0.20 & 0.4 & 238.6 & 113.9 & 214.8 & 340.650 & 0.674 \\
\hline 12 & 160 & 0.25 & 0.6 & 327.7 & 223.6 & 418.9 & 576.941 & 2.191 \\
\hline 13 & 200 & 0.10 & 1.0 & 297.1 & 380.3 & 395.1 & 623.699 & 0.583 \\
\hline 14 & 200 & 0.15 & 0.8 & 448.1 & 372.3 & 402.1 & 707.874 & 1.902 \\
\hline 15 & 200 & 0.20 & 0.6 & 291.1 & 205.0 & 344.3 & 495.284 & 1.241 \\
\hline 16 & 200 & 0.25 & 0.4 & 296.6 & 124.2 & 254.7 & 410.206 & 0.872 \\
\hline$v:$ cutting speed in m/min; $f:$ feed rate in mm/r; $a_{p}:$ depth of cut in mm; m cut- \\
\hline \multicolumn{7}{|c|}{ ting force in N; Ra: average surface roughness in $\mu$ m } \\
\hline
\end{tabular}

Table 5

Range table of cutting force $\mathrm{F}$

\begin{tabular}{|c|c|c|c|}
\hline Fevel & $\mathrm{A}: v$ & $\mathrm{~B}: f$ & $\mathrm{C}: a_{p}$ \\
\hline$K_{1}$ & 612.39 & 413.78 & 305.32 \\
\hline$K_{2}$ & 535.44 & 540.09 & 484.48 \\
\hline$K_{3}$ & 516.35 & 611.38 & 642.32 \\
\hline$K_{4}$ & 559.27 & 658.20 & 791.33 \\
\hline $\mathrm{R}$ & 96.04 & 244.42 & 486.01 \\
\hline Factor order & \multicolumn{3}{|c|}{$\mathrm{C} \rightarrow \mathrm{B} \rightarrow \mathrm{A}$} \\
\hline
\end{tabular}

Commonly, the surface roughness $R a$ was decreased as the increase of cutting speed, and increased as the feed rate and cutting depth. When cutting speed was over $160 \mathrm{~m} / \mathrm{min}$, the rapid wear of the tool caused the cutting force increased, but the serious friction effect at the tool nose and the work-piece would decrease the surface roughness, that was the reason that the $R a$ was small at the speed of $200 \mathrm{~m} / \mathrm{min}$. When the cutting depth was over $0.80 \mathrm{~mm}$, Ra decreased instead. That was maybe because of the high heat softening effect of the material under high cutting depth. The multivariate regression model of roughness was adopted similar as the method of cutting force, and the empirical formula was:

$$
R_{a}=214.863 v^{-0.764} f^{0.592} a_{p}^{0.640} .
$$

\subsection{Chip form}

In the machining process of some kind of difficultto-cut materials with high hardness and low thermal physical properties, such as Titanium alloy, hardened steel and high strength steel, serrated chips often appeared. In this experiment, typical chip form was denoted in Fig. 2. Within the selected range of machining parameters, all the chips were serrated. The cutting force fluctuation caused by the 
chip serrated might cause the vibration of the tool system, which caused the deterioration of the machined surface quality, and the tool wear speed up or damage.

\subsection{Tool wear}

According to the analysis above, comprehensive consideration of surface roughness, cutting efficiency and tool life, a better combination of parameters was as follows: cutting speed $120 \mathrm{~m} / \mathrm{min}$, feed rate $0.15 \mathrm{~mm} / \mathrm{rev}$, cutting depth $0.4 \mathrm{~mm}$. Tool wear experiment was carried out based on this parameter, with cutting time 30 seconds for each step. Relationship between cutting force and time was shown in Fig.3. It indicated that at the beginning of cutting process, the change of cutting force was not significant, due to the slight tool wear. When the cutting time was over 600 $\mathrm{s}$, the changes of cutting force with time was more obvious, which meant that the tool wear was even more serious.
Morphology of the tool wear was observed by confocal laser scanning microscope VK-100, shown in Fig. 4. Worn area of the tool at each cutting step was measured, shown in Fig. 5. It indicated that the initial wear rate of the cutting tool was slightly decreased, but the tool wear became more and more serious with the increase of cutting time.

Table 6

Range table of $R a$

\begin{tabular}{|c|c|c|c|}
\hline Factor & $\mathrm{A}: v$ & $\mathrm{~B}: f$ & $\mathrm{C}: a_{p}$ \\
\hline$K_{1}$ & 2.610 & 1.325 & 1.105 \\
\hline$K_{2}$ & 1.237 & 1.144 & 1.245 \\
\hline$K_{3}$ & 1.458 & 1.967 & 2.275 \\
\hline$K_{4}$ & 1.150 & 2.018 & 1.829 \\
\hline $\mathrm{R}$ & 1.460 & 0.874 & 1.170 \\
\hline Factor order & \multicolumn{3}{|c|}{$\mathrm{A} \rightarrow \mathrm{C} \rightarrow \mathrm{B}$} \\
\hline
\end{tabular}
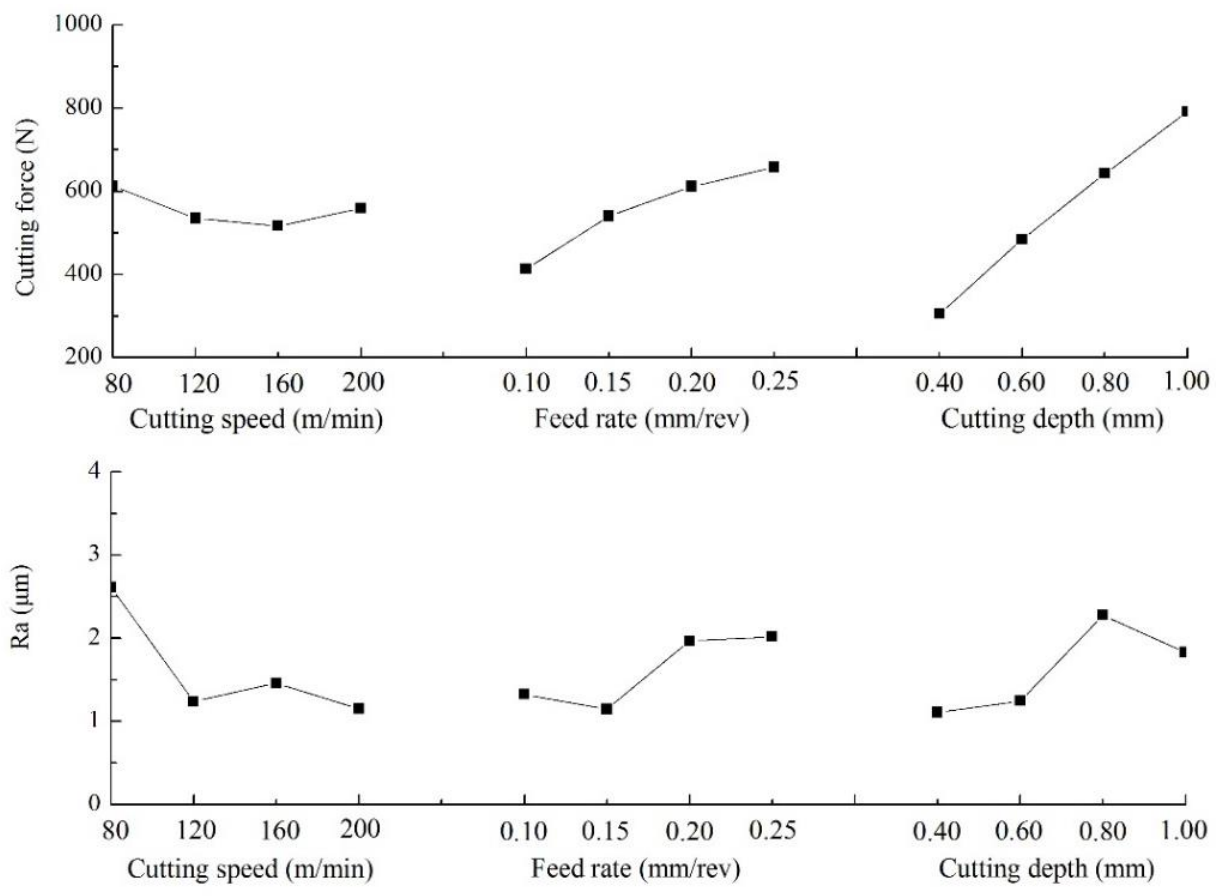

Fig. 1 The trend chart of cutting force and surface roughness $R a$

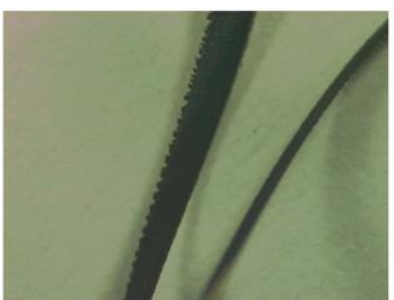

(a) $80 \mathrm{~m} / \mathrm{min}, 0.1 \mathrm{~mm} / \mathrm{rev}, 0.4 \mathrm{~mm}$

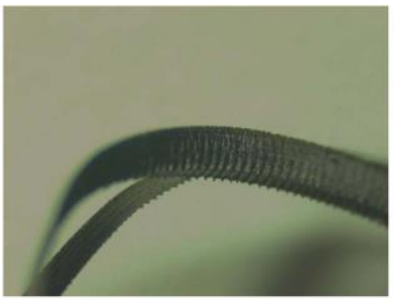

(c) $160 \mathrm{~m} / \mathrm{min}, 0.2 \mathrm{~mm} / \mathrm{rev}, 0.4 \mathrm{~mm}$

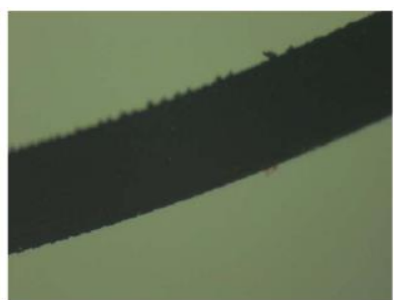

(b) $120 \mathrm{~m} / \mathrm{min}, 0.15 \mathrm{~mm} / \mathrm{rev}, 0.4 \mathrm{~mm}$

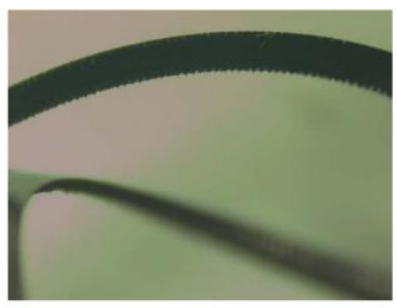

(d) $200 \mathrm{~m} / \mathrm{min}, 0.25 \mathrm{~mm} / \mathrm{rev}, 0.4 \mathrm{~mm}$
Fig. 2 Typical chip formation in the experiments

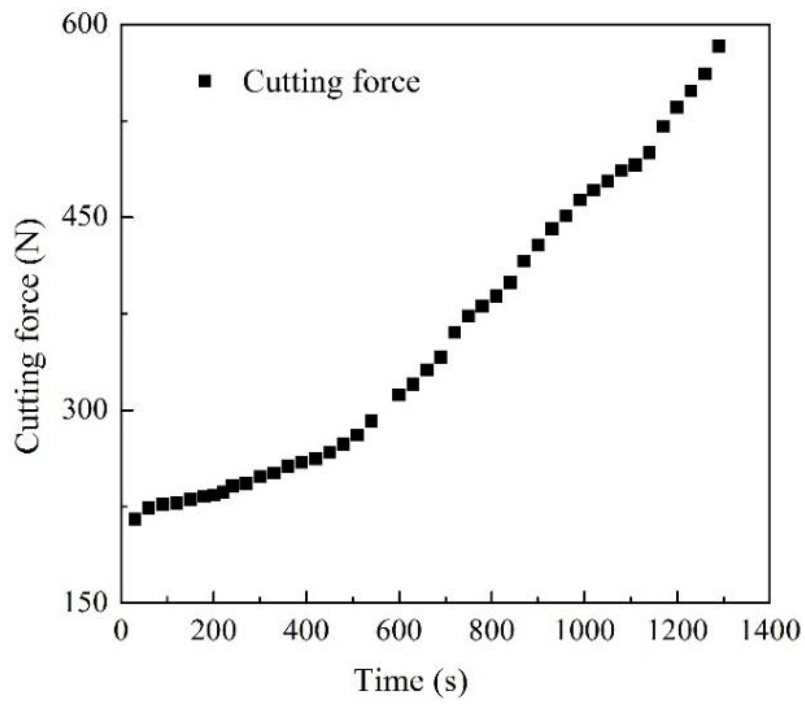

Fig. 3 Relationship between cutting force and time 
(a) $60 \mathrm{~s}$

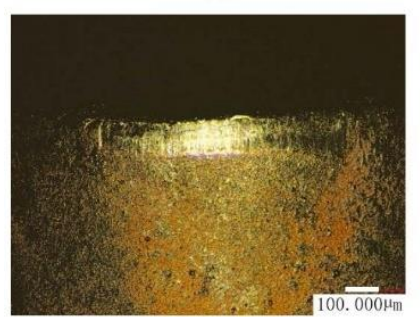

(c) $1020 \mathrm{~s}$

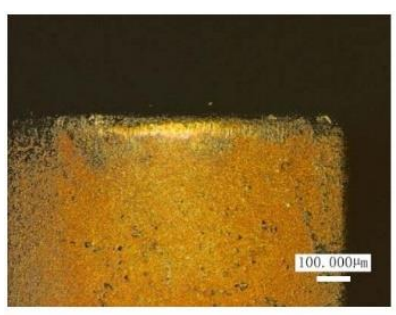

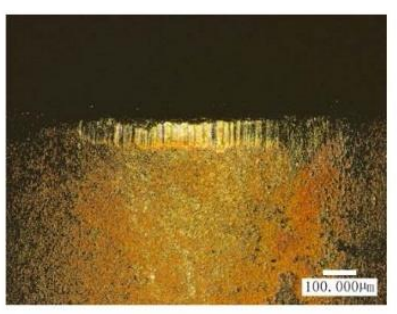

(b) $420 \mathrm{~s}$

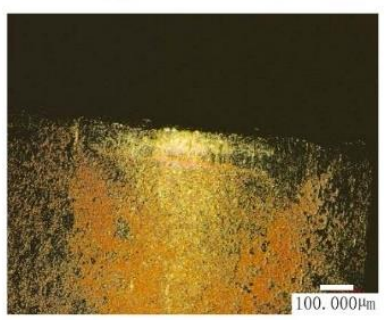

(d) $1500 \mathrm{~s}$
Fig. 4 Morphology of tool wear under different time

During this cutting process, the normal wearing stage of the tool was not obvious, that was mainly because that the strength and toughness of the work piece was high, result in the high cutting force and temperature, so the wear of the tool was serious throughout. The cutting force and temperature were further increased after the early stage wear of the tool, which would accelerate the tool wear, causing the accelerated wear in the later periods. Besides, the tool life under this cutting condition was about $2000 \mathrm{~s}$, which basically fulfilled the needs of the actual production.

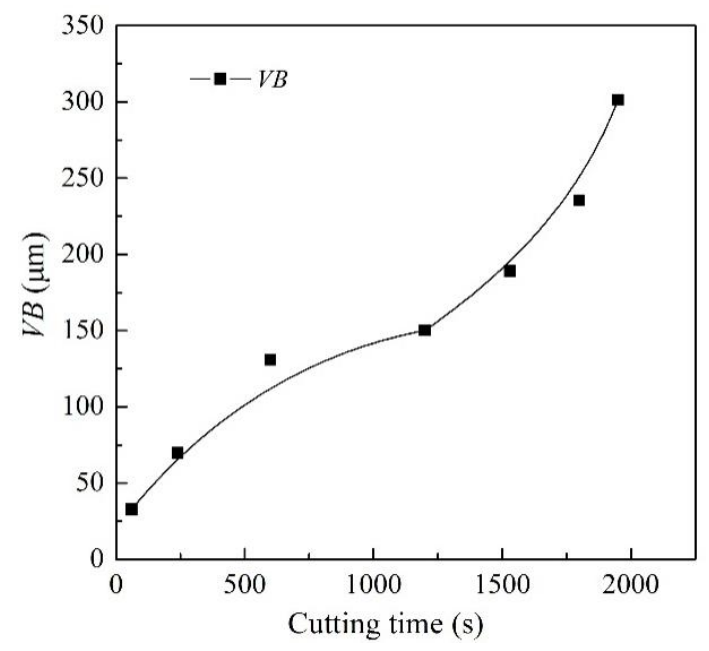

Fig. 5 Tool wear variation with time

\section{Conclusions}

The effects of different turning parameters on cutting force, surface roughness, chip form and tool wear of ultrahigh strength steel were experimentally investigated, and the empirical formula of the cutting force and surface roughness $R a$ were obtained. The main conclusions can be summarized as follows:

1. Cutting forces and surface roughness Ra were decreased as the increase of cutting speed as the material softening and plastic flow caused by high cutting temperature.

2. Cutting forces and surface roughness Ra were increased as the increase of feed rate and cutting depth, that was because of high material removal rate and surface residual area.

3. Within selected range of machining parameters in the experiments, all the chips were serrated.

4. Because of high cutting force and temperature, the normal wearing stage of the tool was not obvious.

\section{Acknowledgements}

This work was supported by "National Natural Science Foundation of China (51505034, 51575305)".

\section{References}

1. Xiong, M.X.; Liew, J.Y.R. 2016. Mechanical behaviour of ultra-high strength concrete at elevated temperatures and fire resistance of ultra-high strength concrete filled steel tubes, Materials \& Design 104: 414-27. http://dx.doi.org/10.1016/j.matdes.2016.05.050.

2. Javidan, F.; Heidarpour, A.; Zhao, X.L.; Minkkinen, J. 2016. Application of high strength and ultra-high strength steel tubes in long hybrid compressive members: Experimental and numerical investigation, ThinWalled Structures 102: 273-85.

http://dx.doi.org/10.1016/j.tws.2016.02.002.

3. Wang, B.; Liu, Z.Q.; Su, G.S.; Song, Q.H.; Ai, X. 2015. Investigations of critical cutting speed and ductileto-brittle transition mechanism for workpiece material in ultra-high speed machining. International Journal of Mechanical Sciences 104: 44-59. http://dx.doi.org/10.1016/j.ijmecsci.2015.10.004

4. Liu, Z.Q.; Ai, X.; Zhang, H.; Wang, Z.T.; Wan, Y. 2002. Wear patterns and mechanisms of cutting tools in high-speed face milling. Journal of Materials Processing Technology 129(1-3):222-6.

http://dx.doi.org/10.1016/S0924-0136(02)00605-2.

5. Abou,-El-Hossein, K.; Olufayo, O.; Mkoko, Z. 2013. Diamond tool wear during ultra-high precision machining of rapidly solidified aluminium RSA 905. Wear 302(1-2):1105-12.

http://dx.doi.org/10.1016/j.wear.2012.12.060.

6. Umbrello, D.; Micari, F.; Jawahir, I.S. 2012. The effects of cryogenic cooling on surface integrity in hard machining: A comparison with dry machining. CIRP Annals - Manufacturing Technology 61(1):103-6. http://dx.doi.org/10.1016/j.cirp.2012.03.052.

7. M'Saoubi, R.; Larsson, T.; Outeiro, J.; Guo, Y. Suslov, S.; Saldana, C.; Chandrasekarc, S. 2012. Surface integrity analysis of machined Inconel 718 over multiple length scales. CIRP Annals - Manufacturing Technology 61(1):99-102.

http://dx.doi.org/10.1016/j.cirp.2012.03.058.

8. Grzesik, W.; Żak, K. 2012. Surface integrity generated by oblique machining of steel and iron parts. Journal of Materials Processing Technology 212(12):2586-96. http://dx.doi.org/10.1016/j.jmatprotec.2012.07.019. 
Pei Yan, Junyi Zhu, Zeyu Peng, Peng Wang, Li Jiao, Xibin Wang

\section{EXPERIMENTAL RESEARCH ON PARAMETER OPTIMIZATION FOR HIGH EFFEICIENCY HARD TURNING OF ULTRAHIGH STRENGTH STEEL $42 \mathrm{CrMo}$}

S u m m a r y

Ultrahigh strength steel was a structural material with extremely high tensile, shear and yield strength. While, it was difficult to machining due to the excellent mechanical properties. There was serious problem in high quality and high efficiency machining of ultrahigh strength steel in actual production. In this paper, the effect of different turning parameters on cutting force, surface roughness, chip form and tool wear during dry turning of a typical ultrahigh strength steel were experimentally investigated, and the cutting parameters were optimized, then the empirical formulas of the cutting force and surface roughness Ra were also obtained. Both the cutting forces and surface roughness Ra were decreased as the increase of cutting speed, and increased as the feed rate and cutting depth. Within the selected range of machining parameters in the experiments, all the chips were serrated. The normal wear stage of the tool was not obviously, and the tool life was about $2000 \mathrm{~s}$, which fulfilled the needs of actual production. This study gave experimental support for the parameter optimization during dry machining of ultrahigh strength steel, comprehensive considering processing efficiency, tool wear and machined surface quality.

Keywords: ultrahigh strength steel, cutting parameter, tool wear, orthogonal method, cutting force.

Received November 26, 2016 Accepted December 07, 2017 